\title{
Abstract
}

Objectives: to evaluate the feasibility and usability of the Senior Fitness Test (SFT) in persons with acquired brain injury.

Methods: A pilot cohort design with a convenience sample of persons with acquired brain injury.

Results: Persons with acquired brain injuries [n=47] were younger than their healthy counterparts [ $n=172]$ were but performed significantly worse on sit to stand, 6 Minute -Walk-Test (6MWT) and $2.45 \mathrm{~m}$ up-and-go. This difference was accentuated in the age groups $>60$ years of age. Persons with acquired brain injuries, divided into subgroups Traumatic Brain Injury (TBI) [n=12] and Cerebral Insult (CI) [n=35], showed significant differences in leg strength, upper extremity flexibility and walking capacity. Persons with $\mathrm{Cl}$ were weaker, less flexible in upper and lower extremities, walked shorter distance and were less mobile. $\mathrm{Cl}$ but not TBI performed significantly worse when compared to healthy elderly persons.

Conclusion: This study indicates that SFT is feasible, safe and useful tool for persons with acquired brain injury, to evaluate physical capacity, endurance, strength and flexibility. The sub maximal test was well tolerated and could be performed by all participants irrespective of age or diagnosis. The distribution of test scores indicates responsiveness to change, and no ceiling or floor effects.

Keywords: acquired brain injury, cerebral insult, senior fitness test, traumatic brain injury 


\section{Senior Fitness Test; a useful tool to measure physical fitness in persons with acquired brain injury}

\section{Introduction}

Physical activity levels are closely related to health and are important to maintain [1]. Lifestyle, lifestyle diseases, or physical inactivity [2-4] may cause acquired brain injury. A long hospitalization may enhance an inactive lifestyle and persons with acquired brain injury resulting in reduced physical fitness as a secondary complication after the acquired brain injury [5-6].

Acquired brain injury $(A B I)$ includes traumatic brain injury $(T B I)$ and non-traumatic brain injuries.

TBI's may be contact, referring to a direct external trauma to the head, or non-contact injuries, referring to acceleration or de-acceleration forces which make the brain move inside the skull causing damage to the same. Non-traumatic brain injuries on the other hand refers to an internal insult, as for example the rupture of a blood vessel causing an internal hemorrhage, or a reduction in blood flow due to clotting, causing brain injury [7].

A minimum level of fitness is a prerequisite to maintain health, activities of daily life and health related quality of life [1]. However, physical fitness after acquired brain injury is not evaluated in the hospitals, so little is known of how primary and secondary influences interact. Maximal endurance or strength is rarely tested in persons with brain injury, because of the risk for complications. A simple submaximal tool, in acute and post-acute clinical care, to evaluate physical form such as strength, endurance, flexibility and balance would therefore be of value.

The Senior Fitness test [SFT] is a test kit consisting of submaximal tests of endurance, strength and flexibility [8]. SFT is used to evaluate physical fitness mainly in older people [9-15], and but has not been used in persons with brain injury. However, some of the items, like 6-Minute-Walk-Test 
[6MWT] and Timed-Up-and-Go [TUG], are frequently used in clinical evaluations of people with acquired brain injuries by physiotherapists. It is therefore reasonable to assume that the total SFT may be a useful screening tool to evaluate the submaximal physical fitness in persons with acquired brain injury, both in acute and post-acute care. The information would be vital in the evaluation and goal settings for persons with acquired brain injury.

The purpose with this study was to evaluate the feasibility of the SFT in persons with acquired brain injury, to evaluate the usability during post-acute rehabilitation and in municipality services. In addition, we wanted to compare the test results in the persons with acquired brain injury, to the results in healthy counterparts. Thus, we would study to what degree physical fitness is reduced in persons with acquired brain injury compared to the physical fitness in a control group and possibly establish norm values for this group.

\section{Methods}

A pilot cohort design with a convenience sample of persons with acquired brain injury. Persons with acquired brain injury were invited, consecutively recruited, and tested in two different settings: at the specialized rehabilitation unit and in community rehabilitation services. Healthy counterparts were recruited from an urban community through advertising. The same experienced person tested all participants in their respective unit.

\section{Ethics}

All participants received verbal and written information about the purpose before the testing, and signed a written consent of voluntary participation. The project was reported to the Norwegian Center for Research Data, reference number 21106/1.

\section{Subjects}

Persons with TBI were recruited from the specialized rehabilitation unit, where they met for a 6 months evaluation post injury. The persons with TBI had a mild-moderate disability, with a BI mean 
20 , range $20-20$, and mainly with cognitive deficits. Persons with $\mathrm{Cl}$ were recruited from the acute hospital, community based services, and specialized rehabilitation, 2 months to 1-year post stroke. They had a mixture of physical and cognitive disability with a BI mean 17.9, range 3-20 (Table 1).

\section{Outcome measure}

The participants are described by age and gender. In addition, activities of daily living (ADL), the presence of cognitive deficits and pain were registered. Cognitive deficits were categorized into intact / reduced, and pain into present or not. Heart rate was registered when performing 6MWT in persons with acquired brain injury.

\section{Senior Fitness Test}

The SFT, developed by Rikli \& Jones in the US for adults $60+[8]$, has been translated into Danish, and this was the version used in this study (9).The SFT is simple to use, it does not require expensive tools or technical expertise, and may be performed in the usual, well-known surroundings. The test consists of six functional measures of strength in arms and legs, endurance, balance, agility and flexibility, and it takes approximately 30-40 minutes to perform. The items are shortly described:

- Chair stand in 30 seconds to measure lower-body strength

- Arm curl to measure upper-body strength; number of biceps curls completed in 30 s. The original weights were $5 \mathrm{lb}[2.27 \mathrm{~kg}]$ for women and $8 \mathrm{lb}[3.63 \mathrm{~kg}]$ for men.

- 6-Minute Walk Test (6MWT) to assess aerobic endurance; distance walked in $\mathrm{m}$. In the original study this was performed in a rectangular shape, divided into 5 yards length measuring a total of 50 yards $[45.7 \mathrm{~m}]$.

- 2-minute step test to assess aerobic endurance, the number of full steps completed in 2 minutes;

- Chair-sit-and-reach test, $\mathrm{cm}$ to assess lower-body flexibility;

- Back scratch test, $\mathrm{cm}$ to measure upper-body flexibility; 
- 2.45 meter up-and-go test, sec to assess agility and dynamic balance;

- Body Mass Index [BMI] [weight/height $\left.{ }^{2}\right]$.

The SFT is tested for reliability, with an ICC [Intra Class Correlation coefficient] ranging from 0.8 to 0.98 on the different items [10-13]. Validity of the different items was tested to a "gold standard", like, for example, chair stand versus one repetition maximum [RM] leg press; arm curl versus combined 1RM biceps, chest and upper back [10]. The association between the gold standard and the items in The SFT ranged from 0.73 to 0.83 . However, there is no gold standard or direct criterion for two of the items, namely in 2.45m up-and-go and back scratch [10-11].

The SFT version was modified and adapted to the Norwegian metric and weight system in items the biceps curl test, the 6MWT and the flexibility test. Normative standards for healthy elderlies exists, confirming comparable normative results between healthy elderly people in the USA and Norway [8$9,15]$.

\section{Barthel Index}

Barthel Index $[B I]$ is a test of primary activities of daily living $[A D L]$ developed by Mahoney and Barthel [16] for measuring functional independence in personal care and mobility. The BI version with a maximum of 20 points was used.

\section{Pulse}

Heart rate was measured with a pulse monitor, Sport tester ${ }^{\mathrm{TM}}$ PE 3000, made by Polar Electro, Finland. In a smaller sample of the subgroups of persons with acquired brain injury pulse in activity was recorded during the $6 \mathrm{MWT}$. The mean of three measurements of the highest pulse rates was recorded.

\section{Statistical analysis}

The statistical analyses performed with the SPSS package for Windows, version 24 [SPSS Inc. Chicago IL]. Standard descriptive statistics mean [SD] and frequencies were used to describe the sample as a 
whole and subgroups. Possible ceiling and floor effects were evaluated by looking at the distribution of responses and from reported skewness and kurtosis of the different items of SFT.

A comparison between the samples acquired brain injury and a normative sample of healthy elderly, was performed with an analysis of variance [ANOVA], as well as sub group analysis. In these subgroup analysis additional associations with cognitive function and intensity/pulse was evaluated with Spearman correlations.

A linear regression analysis evaluating explanatory factors was performed where the items of SFT were consecutively inserted as dependent variables and age, pulse, level of independence in ADL [BI] cognitive function, and subgroups $\mathrm{TBI}$ and $\mathrm{Cl}$ were inserted as independent variables. $\mathrm{A} p$ value $<0.05$ was set as significant.

\section{Results}

In total 47 persons with acquired brain injury participated in this study, of these 12 had Traumatic Brain Injury [TBI] and 35 Cerebral Insult [CI]. In addition, 172 healthy elderly from the earlier SFT study was used to evaluate normative values for SFT.

\section{Description}

Persons with acquired brain injuries were younger and with more males than their healthy counterparts. Furthermore, they were dependent in ADL, had more pain and presented with reduced cognitive function compared to the healthy counter parts [Table 1].

Divided into sub-groups, persons with $\mathrm{Cl}$ were significantly older than persons with $\mathrm{TBI}, 65$ years versus 28 years, had multi-morbidities [ $n=15]$, reported a higher degree pain [ $n=6]$, and were less mobile [Table 1-2]. Males were predominant in the group with TBI [11 / 1] compared to the group with $\mathrm{Cl}$ [22 / 13]. Multi-morbidity was presented as mainly a combination of high blood pressure, 
heart disease and lung disease, in the group of $\mathrm{Cl}$. Persons with TBI had mainly muscle and skeletal problems.

Independence in ADL but reduced cognitive function was registered in all persons with TBI (Table 1). In persons with $\mathrm{Cl}$, on the other hand, $50 \%$ had a reduced cognitive function and participants were to a higher degree dependent in ADL [Table 1].

A subgroup of persons with $\mathrm{CI}[\mathrm{n}=9]$ and TBI [n=8] displayed equal pulse peaks in relation to the performance of 6MWT [Table 2], indicating that the performance was on a moderate to high intensity. Estimated maximal pulse rate [31] indicated that persons with TBI had an intensity of 69\% of their maximal pulse versus $78 \%$ in persons with $\mathrm{Cl}$ during walking.

No floor and ceiling effects of SFT in the different groups could be noted. The distribution of scores were even, skewness and kurtosis ranging between -0.3 to 1.3 and 0.06 to -1.2 respectively.

\section{Group differences in Senior Fitness Test}

Persons with acquired brain injuries were younger than their healthy counterparts were but performed significantly worse on sit to stand, 6MWT and 2.45m up-and-go [Table 29. This difference was accentuated in the age groups $>60$ years of age [Table 3]. Persons with acquired brain injuries, divided into subgroups $\mathrm{TBI}$ and $\mathrm{Cl}$, showed significant differences in leg strength, upper extremity flexibility and walking capacity [Table 2]. Persons with $\mathrm{Cl}$ were weaker, less flexible in upper and lower extremities, walked shorter distance and were less mobile. CI but not TBI performed significantly worse when compared to healthy elderly persons [Table 2].

The items sit to stand, 6MWT, 2.45 up-and-go and back scratch had a medium non-significant association, $r=0.3$ to 0.4 , with intensity /pulse, whereas cognitive function had a small but significant association, $r=0.2$, with back scratch and chair sit and reach. 
The linear regression analysis of the different items SFT as independent variables and acquired brain injury, age, $\mathrm{BI}$ and cognition as independent was a significant model for three items: endurance, mobility and strength. For endurance, estimated with the 6MWT, main explanatory contributors were age $[B=-1.93, p=0.07]$, cognition $[B=131.25, p=0.0001]$ and $B \mid[B=41.75, p=0.00019]$, explaining 95\%. For mobility, estimated with 2.45 up-and-go, main explanatory contributor was age $[B=0.14, p=0.03]$ explaining $51 \%$. Finally for strength, estimated with sit to stand, main contributors were $\mathrm{BI}[\mathrm{B}=0.91, \mathrm{p}=0.0001]$ and age $[\mathrm{B}=-0.09, \mathrm{p}=0.04]$ explaining $60 \%$.

The items responsiveness was evaluated in a smaller sample recruited from the rehabilitation unit. The persons with acquired brain injury in this group experienced less physical disability $(\mathrm{BI}=20)$ and their SFT scores at baseline (for example 6MWT: 765m / 577m, 2.45 up and go: 3.4 / 5.9) were in general better, independent of $\mathrm{TBI}$ or $\mathrm{Cl}$. The results in this small subgroup indicate change independent of age [Table 4].

\section{Discussion}

This study indicates that SFT is feasible, safe and may be considered a useful tool for persons with acquired brain injury in both specialist and community based rehabilitation, to evaluate physical capacity, endurance, strength and flexibility. The sub maximal test was well tolerated and could be performed by all participants irrespective of age or institution. The distribution of test scores indicates responsiveness to change, and no ceiling or floor effects.

The test results indicate a lower performance in persons with acquired brain injury compared to a healthy group of elderly. However, sub-group analysis indicated that persons with $\mathrm{Cl}$ performed significantly poorer on most items, except arm curl, versus persons with TBI and healthy counterparts [Table 2]. Persons with TBI had a similar and even better physical capacity than the healthy elderly. The results are in line with other studies indicating poor physical capacity in persons with $\mathrm{Cl}$ compared to healthy counterparts [17-18]. 
The difference between persons with $\mathrm{TBI}$ and $\mathrm{Cl}$ was not expected, but there may be several explanations to this difference; one is age and disability / dependence in ADL, which were explanatory factors in the models for endurance and mobility. The accumulation of multi-morbidities before debut of $\mathrm{Cl}$ is another, influencing both physical capacity and physical activity patterns in a negative way [19-20]. In addition, inactivity patterns have been shown to be enhanced in acute care, which may continue the negative development regarding dependence in ADL and reduced physical capacity [5-6]. Fear that activity might provoke a new stroke may also be related to the inactivity patterns, as well as physiological explanations to the decreased activity patterns related to cardiac reserves and muscle metabolism [21-22]. Persons with TBI, on the other hand, had few or no pre morbidities and were young and active persons before their trauma in this study [Table1]. Many of the participants with TBI exercised on a relatively high level, and the reason for rehabilitation was mainly cognitive deficits [Table 1].

Multi-morbidity, a combination of high blood pressure, heart disease and lung disease, alternatively muscle and skeletal problems, were similar in persons with acquired brain injury and healthy counterparts, although age dependent, so that with increasing age more multi morbidities [23]. However, there was less morbidities in the TBI group than in the $\mathrm{Cl}$ and healthy elderly persons groups [Table 1].

The fact that TBI and a healthy population of elderly had the same results may be explained by the cognitive deficit persons with TBI presented. This deficit may influence physical performance and explain why reasonably fit younger persons perform on equal level as their healthy elderlies. From this perspective, persons with TBI performed reasonably well in view of a serious trauma and cognitive deficits [23]. Healthy counterparts' reasonably good performance despite ageing and multimorbidities indicates that this group of elderly maintained their function, indicating an active life style. The results verifies $\mathrm{Cl}$ as a serious disease / trauma with high risk of disability irrespective of age leading to inactivity [19]. 
Persons with $\mathrm{Cl}$ used more energy in order to perform the 6MWT than persons with $\mathrm{TBI}$, underlining the difference between the two sub-groups related to endurance. However, both $\mathrm{Cl}$ and TBI used reasonably high effort in performing the test and when looking at the whole sample acquired brain injuries [Table 1]. Disability rather than an age seem to explain reduced performance $>70$ years of age $[9,11,15]$.

The results of this small study must be interpreted with caution. There were difficulties in recruiting volunteers for testing in the clinic, indicating problems with transport back and forth from home. Participation in activities and training outside the home may be perceived as a huge barrier for persons with acquired brain injury [31]. The persons who were positive to participate in this study may have been less physically disabled than a general population of persons with brain injury. On the other hand, cognitive decline was present in a majority of participants, which indicates that SFT is both feasible and useful for persons with cognitive decline.

\section{Conclusion}

The Senior Fitness Test is a sub maximal test kit for physical fitness. It is simple to use in the clinical setting and has no floor or ceiling effect. The SFT is also sensitive / responsive for changes in persons with acquired brain injury. The test results underline SFT's usefulness, not only in the elderly population but also in $\mathrm{Cl}$ - and the younger Traumatic Brain injury patients.

\section{Declaration of interest}

The authors report no declarations of interest 


\section{References}

1 Myers J, Prakash M, Froelicher V, Do D, Partington S, Atwood JE. Exercise capacity and mortality among men referred for exercise testing. N Engl J Med. 2002; 346(11):793-801.

2 Boehme AK, Esenwa C, Elkind MS. Stroke Risk Factors, Genetics, and Prevention. Circ Res 2017; 120 (3): 472-495.

3 Feigin VL, Barker-Collo S, Krishnamurthi R, Theadom A, Starkey N. Epidemiology of ischaemic stroke and traumatic brain injury. Best Pract Res Clin Anaesthesiol 2010; 24 (4): 485-94.

4 Hwang HF, Cheng CH, Chien DK, Yu WY, Lin MR. Risk Factors for Traumatic Brain Injuries During Falls in Older Persons. J Head Trauma Rehabil 2015; 30 (6): E9-17.

5 Moore SA, Hallsworth K, Plötz T, Ford GA, Rochester L, Trenell MI. Physical Activity, Sedentary Behaviour and Metabolic Control following Stroke: A Cross-Sectional and Longitudinal Study. PLOs One 2013;8(1):e55263.

6 Kunkel D, Fitton C, Burnett M, Ashburn A. Physical inactivity post-stroke: a 3-year longitudinal study. Disabil Rehabil 2014:14:1-7.

7 Giustini A, Pistarini C, Pisoni C. Traumatic and non-traumatic brain injury. In Handbook of Clinical Neurology, Ed Barnes MP, Good DC. Elsevier; 2013; 110: 401-409

8 Rikli RE, Jones CJ. Senior Fitness Test Manual. Champaign, IL: Human Kinetics; 2001.

9 Rikli RE, Jones J, translated by Hansen T. Senior Fitness Test. Physical fitness of older adults manual and reference values (Fysisk formåen hos eldre-manual og referance værdie). København: FADL's Forlag; 2004.

10 Rikli RE, Jones $\mathrm{CJ}$. The development and validation of a functional fitness test for communityresiding older adults. JAPA 1999; 7: 129-161.

11 Rikli RE, Jones CJ. Functional fitness normative scores for community-residing older adults, ages 60-94. JAPA 1999; 7: 162-181.

12 Todde F, Melis F, Mura R, Pau M, Fois F, Magnani S, Ibba G, Crisafulli A, Tocco F. A 12-Week Vigorous Exercise Protocol in a Healthy Group of Persons over 65: Study of Physical Function by means of the Senior Fitness Test. Biomed Res Int 2016; 2016: 7639842

13 Brovold T, Skelton DA, Bergland A. Older adults recently discharged from the hospital: effect of aerobic interval exercise on health-related quality of life, physical fitness, and physical activity. J Am Geriatr Soc 2013; 61 (9): 1580-5.

14 Hesseberg K, Bentzen $\mathrm{H}$, Bergland A. Reliability of the senior fitness test in communitydwelling older people with cognitive impairment. Physiother Res Int 2015; 20 (1): 37-44.

15 Langhammer B, Stanghelle JK. Functional fitness in elderly Norwegians measured with the Senior Fitness Test. Adv Physiother 2011; 13(4):137-144.

16 Mahoney FI, Barthel DW. Functional evaluation: the Barthel Index. Md State Med J 1965; 14 : 61-5.

17 Dunn A, Marsden DL, Van Vliet P, Spratt NJ, Callister R. Independently ambulant, communitydwelling stroke survivors have reduced cardiorespiratory fitness, mobility and knee strength compared to an age- and gender-matched cohort. Top Stroke Rehabil 2017; 24 (3): 163-169. 
18 Pandey A, Patel MR, Willis B, Gao A, Leonard D, Das SR, Defina L, Berry JD. Association Between Midlife Cardiorespiratory Fitness and Risk of Stroke: The Cooper Center Longitudinal Study. Stroke 2016; 47 (7):1720-6.

19 Gallacher KI, Batty GD, McLean G, Mercer SW, Guthrie B, May CR, Langhorne P, Mair FS. Stroke, multimorbidity and polypharmacy in a nationally representative sample of 1,424,378 patients in Scotland: implications for treatment burden. BMC Med 2014; 03 (12): 151.

20 Baert I, Daly D, Dejaeger E, Vanroy C, Vanlandewijck Y, Feys H. Evolution of cardiorespiratory fitness after stroke: a 1-year follow-up study. Influence of prestroke patients' characteristics and stroke-related factors. Arch Phys Med Rehabil 2012; 93 (4): 669-76.

21 Jakovljevic DG, Moore SA, Tan LB, Rochester L, Ford GA, Trenell MI. Discrepancy between cardiac and physical functional reserves in stroke. Stroke 2012; 43 (5): 1422-5.

22 Loureiro APC, Langhammer B, Gjøvaag T, Ihle-Hansen H, Guarita-Souza LC. Skeletal muscle metabolism after stroke: A comparative study using treadmill and overground walking test. J Rehabil Med. 2017 ;7;49(7):558-564.

23 Bell SP, Saraf AA. Epidemiology of Multimorbidity in Older Adults with Cardiovascular Disease. Clin Geriatr Med 2016; 32 (2): 215-26.

24 Butler AA; Menant JC; Tiedemann AC; Lord SR. Age and gender differences in seven tests of functional mobility. J Neuroeng Rehabil 2009; 30(6): 31. 
Table 1 Description of participants: Acquired brain injury, divided into TBI / stroke and healthy counterparts.

\begin{tabular}{|c|c|c|c|c|}
\hline & $\begin{array}{l}\text { AQUIRED BRAIN } \\
\text { INJURY }(n=47)\end{array}$ & $\begin{array}{l}\text { TRAUMATIC BRIAN } \\
\text { INJURY }(n=12)\end{array}$ & $\begin{array}{l}\text { STROKE } \\
(n=35)\end{array}$ & $\begin{array}{l}\text { HEALTHY } \\
\text { ELDERLY } \\
\text { (n=172) }\end{array}$ \\
\hline AGE (years) & $55(29.5)$ & $28(11.8)$ & $65(16.4)$ & $73(5.8)$ \\
\hline $\begin{array}{l}\text { HEIGTH /WEIGHT } \\
(\mathrm{m} / \mathrm{kg})\end{array}$ & $\begin{array}{l}177.7(7.7) / \\
80.7(10.6)\end{array}$ & $\begin{array}{l}181.5(7) / \\
81.3(10.2)\end{array}$ & $\begin{array}{l}175.5(7.5) / \\
80.3(11.2)\end{array}$ & $\begin{array}{l}168.6(8.4) / \\
70.4(12.0)\end{array}$ \\
\hline BMI & $25.4(3.6)$ & $24.0(2.8)$ & $25.9(3.8)$ & $24.6(3.2)$ \\
\hline MALE & 33 (70.2\%) & $11(92 \%)$ & $22(63 \%)$ & $48(28 \%)$ \\
\hline BARTHEL INDEX & $18.4(4.1)$ & $20(0)$ & $18(4.5)$ & $20(0)$ \\
\hline PAIN (n, present) & $6(13 \%)$ & 0 & $6(17 \%)$ & - \\
\hline PULSE & $128(29.5)$ & $130(32.7)$ & $126(28.1)$ & - \\
\hline $\begin{array}{l}\text { COGNITION } \\
\text { (n, reduced) }\end{array}$ & $30(64 \%)$ & $12(100 \%)$ & 18 (51\%) & 0 \\
\hline $\begin{array}{l}\text { MULTIMORBIDITY } \\
\text { (n) }\end{array}$ & $18(38 \%)$ & $3(25 \%)$ & 15 (43\%) & $103(60 \%)$ \\
\hline
\end{tabular}


Table 2 Test results of the different items of the Senior Fitness Test in the three groups: Traumatic Brain Injury (TBI), stroke and Healthy Elderly presented I mean scores, SD and $p$-values set at $p<0.05$.

\begin{tabular}{|c|c|c|c|c|c|}
\hline SENIOR FITNESS TEST: & TBI $(n=12)$ & $\begin{array}{l}\text { STROKE } \\
(n=35)\end{array}$ & p-value & $\begin{array}{l}\text { HEALTHY ELDERLY } \\
(\mathrm{n}=172)\end{array}$ & p-value \\
\hline SIT TO STAND (n; in 30s) & $17.6(4.6)$ & $11.9(6.5)$ & 0.01 & $15.8(5.1)$ & \\
\hline ARM CURL (n; in 30s) & $16.8(7.0)$ & $16.3(7.8)$ & 0.8 & $15.2(3.7)$ & $\begin{array}{l}0.09 \\
0.001\end{array}$ \\
\hline 2.45M UP AND GO (s) & $4.7(1.3)$ & $8.6(7.7)$ & 0.09 & $5.0(1.2)$ & 0.001 \\
\hline LOWER EXTREMITY FLEX $(\mathrm{cm})$ & $-3.3(12.2)$ & $-7.3(13.0)$ & 0.2 & $2.7(12.3)$ & 0.001 \\
\hline UPPER EXTREMITY FLEX (cm) & $-7.0(8.9)$ & $-15.8(11.9)$ & 0.03 & $-4.3(10.1)$ & 0.001 \\
\hline $6 \mathrm{MWT}(\mathrm{m})$ & $676.3(76.0)$ & $439.3(224.1)$ & 0.001 & $598.3(93.4)$ & 0.01 \\
\hline 2 MIN HIP FLEX (n) & - & $94(58.4)$ & - & $95.6(22.0)$ & 0.2 \\
\hline BMI & $24.0(2.8)$ & $25.9(3.8)$ & 0.12 & $24.6(3.2)$ & 0.001 \\
\hline
\end{tabular}


Table 3 Senior Fitness Test in groups' acquired brain injury and healthy elderly divided into age

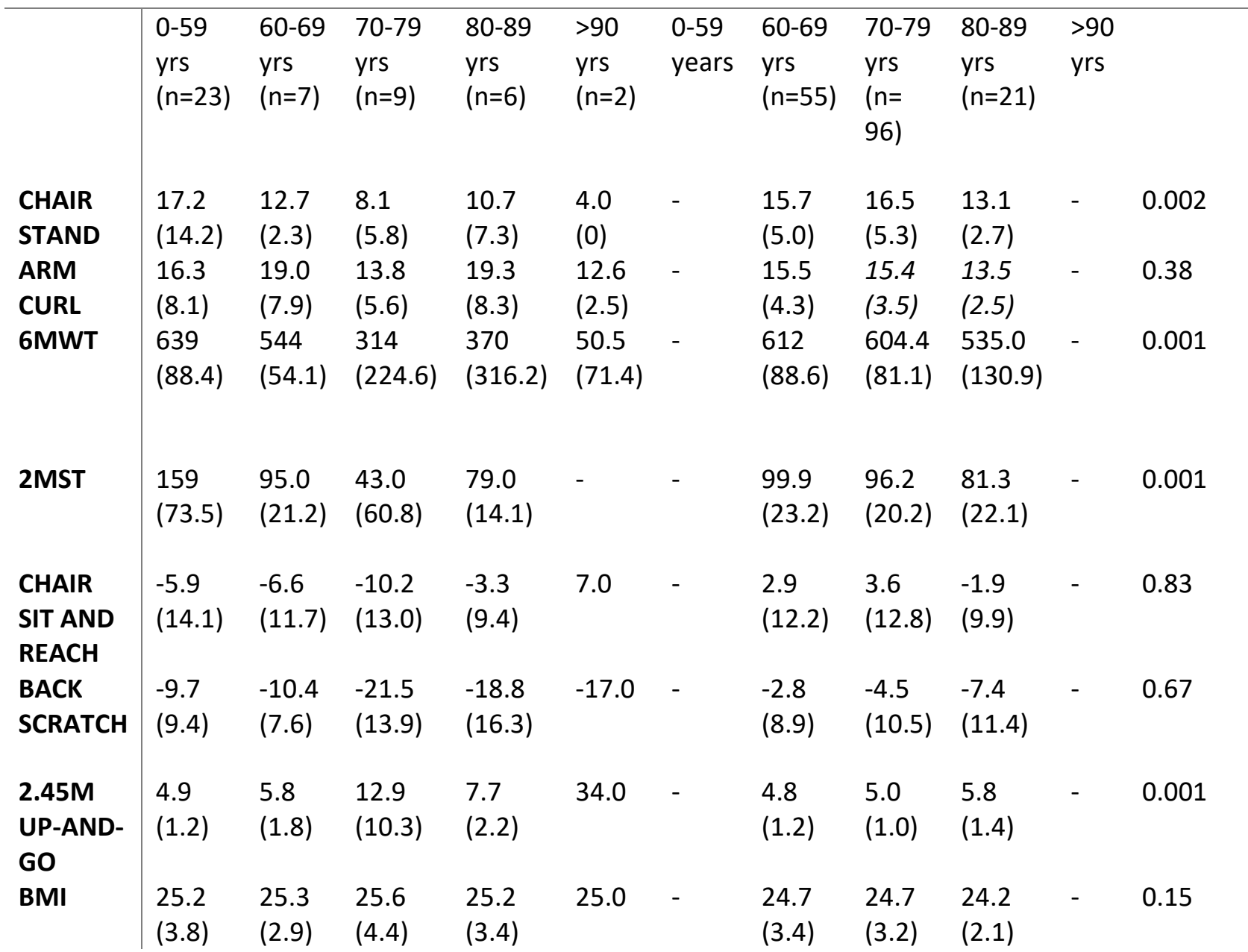

${ }^{1}$ Langhammer B, Stanghelle JK. Functional fitness in elderly Notrwegians measured with the Senior Fitness Test. Adv Phys Ther 2011;13:137-144. 
Table 4 Change scores on the items of the Senior Fitness Test (SFT) in persons with Traumatic Brain Injury (TBI), and persons with stroke before and after a training episode, mean scores (SD).

\begin{tabular}{|c|c|c|c|c|}
\hline SENIOR FITNESS TEST: & $\begin{array}{l}\text { TBI TEST } 1 \\
(n=12)\end{array}$ & $\begin{array}{l}\text { TBI TEST } 2 \\
(n=3)\end{array}$ & $\begin{array}{l}\text { STROKE TEST } 1 \\
(n=35)\end{array}$ & $\begin{array}{l}\text { STROKE TEST } 2 \\
(n=10)\end{array}$ \\
\hline SIT TO STAND (n, in 30s) & $17.4(4.7)$ & $23.7(1.2)$ & $11.9(6.5)$ & $16.6(3.5)$ \\
\hline ARM CURL (n, in 30s) & $17.1(7.3)$ & $23.7(7.4)$ & $16.3(7.8)$ & $16.0(3.1)$ \\
\hline 2.45M UP AND GO (s) & $4.6(1.3)$ & $3.2(0.4)$ & $8.6(7.7)$ & $4.9(0.8)$ \\
\hline LOWER EXTREMITY FLEX $(\mathrm{cm})$ & $-1.3(10.5)$ & $-1.8(11.8)$ & $-7.3(13.0)$ & $-11.1(16.5)$ \\
\hline UPPER EXTREMITY FLEX (cm) & $-7.2(9.4)$ & $4.7(4.7)$ & $-15.8(11.9)$ & $-14.9(8.9)$ \\
\hline $6 \mathrm{MWT}$ & $682.5(76.5)$ & $789.3(52.9)$ & $439.3(224.1)$ & $628.1(56.5)$ \\
\hline BMI & $24.5(2.5)$ & $25(-)$ & $25.9(3.8)$ & $26.0(3.6)$ \\
\hline
\end{tabular}

